Article

\title{
PLA- and PLA/PLGA-Emulsion Composite Biomaterial Sheets for the Controllable Sustained Release of Hydrophilic Compounds
}

\author{
Hitomi Moroishi, Seiichi Sonotaki and Yoshihiko Murakami * \\ Department of Organic and Polymer Materials Chemistry, Tokyo University of Agriculture and Technology, \\ 2-24-16 Naka-cho, Koganei-shi, Tokyo 184-8588, Japan; muralab-tuat@y3.dion.ne.jp (H.M.); \\ s162591s@st.go.tuat.ac.jp (S.S.) \\ * Correspondence: muray@cc.tuat.ac.jp; Tel.: +81-42-388-7387
}

Received: 26 November 2018; Accepted: 17 December 2018; Published: 19 December 2018

\begin{abstract}
In the present study, by spin-coating a solution containing w/o (water-in-oil) emulsions and hydrophobic polymers, we obtained sheets possessing uniformly dispersed w/o emulsions. We performed release experiments for more than 100 days and clarified the effects of the number of layers, the sheet-forming polymers (polylactide (PLA), poly(lactic-co-glycolic acid (PLGA)), the ratio of organic solvent to water, and the composition of block copolymers on the release properties of the sheets. For a variety of sheets, we successfully achieved the sustained release of compounds from the sheets for 100-150 days. The sustained-release of compounds occurred because the compounds had to diffuse into polymer networks after their release from the emulsions. Interestingly, we observed an inflection point in the release profiles at around 50 days; that is, the sheet exhibited a "two-step" release behavior. The results obtained in the present study provide strong evidence for the future possibility of the time-programmed release of multiple compounds from sheets.
\end{abstract}

Keywords: sheet; emulsion; sustained release; biomaterial; PLA; PLGA

\section{Introduction}

Developing a host of biomaterials that stably incorporate hydrophilic biomacromolecules (e.g., proteins) and release them in a sustained manner is important for the effective differentiation and growth of cells in tissue engineering. In general, it is difficult to control the sustained-release property of gel-type biomaterials because the release of compounds from hydrogels depends mainly on two phenomena: the degradation of the hydrogels and the diffusion of the compounds through the hydrogels. Both these phenomena can be partially regulated by tuning the hydrogels' properties, such as the charge and crosslink density. However, it is difficult to control the diffusion and the degradation precisely, because the factors affecting them, such as $\mathrm{pH}$ and body-fluid levels, are variable in the body. By contrast, sheets have several advantages over conventional gels: (1) sheets have a large contact area relative to drug-targeting sites, (2) the shape and size of sheets are easily adjustable, (3) sheets perform well in surgery, and (4) molecular interactions, such as the Van der Waals force, can facilitate the gentle adhesion of sheets to body tissues without an inflammatory reaction at the tissue surface. The properties of sheets, including their flexibility, strength, biocompatibility, and degradation rate, can be altered through both the blending of several substances [1-5] and the formation of porosities $[1,6,7]$. Because of these properties, sheets are attractive for use in biomedical applications, such as wound-dressing [8-12] and sustained drug release [13-18]. Although there have been a variety of reports on hydrophobic sheets stating that they can incorporate and release hydrophobic drugs, the incorporation and release of hydrophilic compounds from sheets remains 
difficult $[19,20]$. Therefore, there is an urgent need for the development of a novel biomaterial that can incorporate and release hydrophilic compounds.

To achieve the successful incorporation and release of drugs, we have developed a novel approach for the construction of functional biomaterials. We have applied this approach to the chemical or physical conjugation of functional units (such as amphiphilic block copolymers or their self-assemblies) to base materials, including gels [21-28], sheets [29-31], and particles [32-36]. For example, the covalent incorporation of trilayered polymeric micelles $[37,38]$ with hydrophilic inner cores into gels gave them the ability to release hydrophilic compounds [24]. Of the three types of hybrid materials, sheets can—using our approach—be easily prepared to contain compound-loading sites within them. Basically, amphiphilic block copolymers are assembled and consequently result in stable droplets ( $w / o$ emulsion) with a hydrophilic inner core in organic solvents. By spin-coating a solution containing a w/o (water-in-oil) emulsion and hydrophobic polymers, we can easily obtain sheets possessing uniformly dispersed w/o emulsions (Figure 1). We have reported the effects of preparation conditions on, for example, the stability $[29,30]$ and the dispersity [30] of inner cores formed from w/o emulsions, the rheological properties [31], and the degradation properties [31]. In addition, although we conducted preliminary release experiments [29,31], the release properties of the sheets were not fully determined. In the present study, we performed release experiments for more than 100 days and clarified, in detail, the effects that the number of layers, the sheet-forming polymers, the ratio of organic solvent to water, and the composition of block copolymers on the release properties of sheets. Interestingly, we found that the sheets successfully exhibit a "two-step" release behavior. To our knowledge, this is the first report on sheets that exhibit a two-step release behavior from uniformly dispersed compound-loading sites.

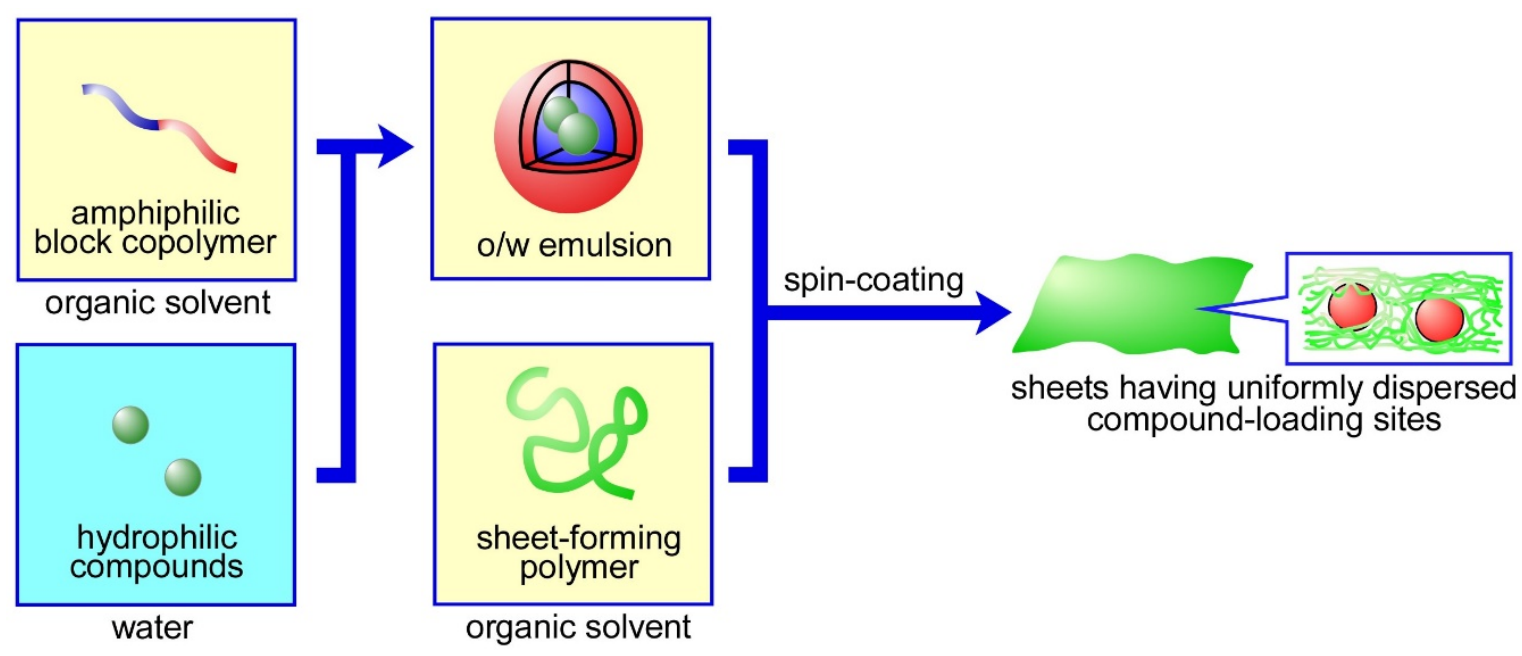

Figure 1. The preparation of sheets with uniformly dispersed compound-loading sites.

\section{Materials and Methods}

\subsection{Materials}

Amphiphilic block copolymers and methoxy-terminated poly(ethylene glycol)-block-poly ( $\varepsilon$-caprolactone) (PEG- $b$-PCL), with different compositions, were previously synthesized by anionic ring-opening polymerization of both ethylene oxide and $\varepsilon$-caprolactone [29], as listed in Table 1. Fluorescein isothiocyanate-dextran (FITC-dex, average molecular weight: 20,000) was purchased from Sigma-Aldrich. Poly(vinyl alcohol) (PVA, degree of polymerization: 500, saponification degree: 86-90 $\mathrm{mol} \%$ ) and PLGA (poly(lactic-co-glycolic acid), monomer ratio of lactide to glycolide: 3, average molecular weight: 20,000) were purchased from Wako Pure Chemical Industries, Ltd. (Osaka, Japan). PLA (average molecular weight: 300,000) was purchased from Polysciences Inc. (Warrington, PA). All other reagents were of analytical grade and were used without further purification. 
Table 1. The different compositions of poly(ethylene glycol)-block-poly(e-caprolactone) (PEG-b-PCL) used in this study.

\begin{tabular}{cccccc}
\hline \multirow{2}{*}{$\operatorname{Code}^{1}$} & PEG (Including Methoxy Terminus) & PCL & \multicolumn{2}{c}{ PEG- $b$-PCL } \\
\cline { 2 - 5 } & $\boldsymbol{M}_{\mathbf{n}}{ }^{2}$ & $\boldsymbol{M}_{\mathbf{w}} \boldsymbol{M}_{\mathbf{n}}{ }^{2}$ & $\boldsymbol{M}_{\mathbf{n}}{ }^{3}$ & $\boldsymbol{M}_{\mathbf{n}}{ }^{2,3}$ & $\boldsymbol{M}_{\mathbf{w}} / \boldsymbol{M}_{\mathbf{n}}{ }^{\mathbf{2}}$ \\
\hline $1.6 \mathrm{k}-0.7 \mathrm{k}$ & 1600 & 1.11 & 700 & 2300 & 1.11 \\
$1.5 \mathrm{k}-1.9 \mathrm{k}$ & 1500 & 1.10 & 1900 & 3400 & 1.24 \\
$3.0 \mathrm{k}-0.6 \mathrm{k}$ & 3000 & 1.05 & 600 & 3600 & 1.08 \\
$3.2 \mathrm{k}-1.9 \mathrm{k}$ & 3200 & 1.04 & 1900 & 5100 & 1.11 \\
$2.9 \mathrm{k}-3.8 \mathrm{k}$ & 2900 & 1.05 & 3800 & 6700 & 1.13 \\
$4.2 \mathrm{k}-8.1 \mathrm{k}$ & 4200 & 1.04 & 8100 & 12,300 & 1.19 \\
\hline 1
\end{tabular}

${ }^{1}$ Code $a-b$ represents a block copolymer with a composition of PEG $M_{\mathrm{n}}(a)$ and PCL $M_{\mathrm{n}}(b),{ }^{2} \mathrm{GPC},{ }^{31} \mathrm{H}$ NMR.

\subsection{Preparation of the Sheets}

We prepared sheets in which either w/o emulsions or w/o emulsions containing fluorescent hydrophilic polymers were dispersed. FITC-dextran was used as a fluorescent indicator for observing the release properties of the sheets. The organic solvent used was a dichloromethane-toluene mixed organic solvent, whose density was adjusted to $1.00 \mathrm{~g} / \mathrm{cm}^{3}$. First, in the presence of the polymeric surfactant PEG- $b$-PLA $(10 \mathrm{w} / \mathrm{v} \%)$, the $\mathrm{w} / \mathrm{o}$ emulsion $(1 \mathrm{~mL})$ was prepared by sonicating both the organic solvent and an aqueous PVA solution $(1 \mathrm{w} / \mathrm{v} \%$ ) for $5 \mathrm{~min}$ in an ice bath (PVA was used as an emulsion stabilizer). The volume ratio of the organic solvent over the aqueous solution was 399 or 39. Next, the obtained w/o emulsion $(1 \mathrm{~mL})$ was added to $10 \mathrm{~mL}$ of the organic solvent containing sheet-forming polymers (PLA $(1-3 \mathrm{w} / \mathrm{v} \%)$ or PLA $(2 \mathrm{w} / \mathrm{v} \%)$ with PLGA $(1-4 \mathrm{w} / \mathrm{v} \%)$ ). The concentration of each polymer corresponded to the value in the final solution after mixing the emulsion and organic solvent. We then obtained a thin sheet by spin-coating $1 \mathrm{~mL}$ of the solution at $2000 \mathrm{rpm}$ for $5 \mathrm{~min}$ on an aluminum substrate, which was cleaned with MilliQ water and acetone prior to use (if desired, multi-layered sheets can be prepared through a repetition of the procedures).

\subsection{Characterization of the Emulsions and Sheets}

The stability of the emulsion was determined through static observation and dynamic light scattering (DLS), using the Zetasizer Nano-ZS (Malvern Instruments, Worcestershire, UK). The thickness of the sheet was determined by a laser confocal displacement meter (LT-9000, KEYENCE Co., Tokyo, Japan). The dispersion of the emulsion in the sheets was observed using a fluorescent microscope (BZ-9000, KEYENCE Co., Tokyo, Japan, $\lambda_{\mathrm{ex}}=470 \mathrm{~nm}, \lambda_{\mathrm{em}}=535 \mathrm{~nm}$ ).

\subsection{Release of FITC-Dex from the Sheets in Which W/O Emulsions Containing FITC-Dex Were Dispersed}

The sheets (for which the layer number was 11) obtained in the previous section were immersed in PBS buffer $\left(100 \mathrm{~mL}, 10 \mathrm{mM}, \mathrm{pH} 7.4,37^{\circ} \mathrm{C}\right)$. The release of FITC-dex from the sheets was monitored using a fluorescence spectrometer $\left(\lambda_{\mathrm{ex}}=495 \mathrm{~nm}, \lambda_{\mathrm{em}}=519 \mathrm{~nm}\right)$.

\section{Results and Discussion}

\subsection{Preparation and Characterization of the Sheets in Which W/O Emulsions Were Dispersed}

In the present study, we aimed to develop biomaterial sheets with uniformly dispersed inner spaces, in which it would be possible to load hydrophilic compounds by spin-coating a solution containing both w/o emulsions prepared from assembled block copolymers (PEG-b-PLA) and sheet-forming hydrophobic polymers (PLA and PLGA). For the polymeric units that form the block copolymers, we selected PEG and PCL, because PEG is a biocompatible polymer that has been used as a non-immunogenic modifier for proteins and drugs [39-43], whereas PCL is a biodegradable polymer that has been used in the preparation of various biomaterials [44-47]. We used PLA and PLGA as sheet-forming polymers because PLA [48-50] and PLGA [51-53] have been frequently used 
for the preparation of polymeric biomaterials, because of their biocompatibility and easily controllable degradation properties. The $\mathrm{w} / \mathrm{o}$ emulsions had to be highly stable in order to form uniformly dispersed inner spaces in the sheets, during the sheet preparation process. An emulsion is a system consisting of two immiscible liquid phases, one of which (the dispersed phase) is dispersed throughout the other (the continuous phase) in stable, small droplets. All the droplets will clump together and phase separation will occur over time because the emulsion is usually unstable. Macroscopic separation of the phases is commonly prevented by using suitable organic solvents, stabilizers, surfactants, and so on. One of the easiest methods to increase the stability of an emulsion is the use of mixed organic solvents, whose density is adjusted to $1.00 \mathrm{~g} / \mathrm{cm}^{3}$, as the phase separation of the emulsion is unlikely to occur when the difference in density between the two the phases is nearly equal to zero, because of the thermodynamically high stability of the emulsion $[29,32]$. Through static observations of the stability of the w/o emulsions, we found that an unstable emulsion was obtained when the block copolymers coded as $1.6 \mathrm{k}-0.7 \mathrm{k}$ and $3.0 \mathrm{k}-0.6 \mathrm{k}$ were used. By contrast, a stable emulsion was formed when the block copolymers coded as $1.5 \mathrm{k}-1.9 \mathrm{k}, 3.2 \mathrm{k}-1.9 \mathrm{k}, 2.9 \mathrm{k}-3.8 \mathrm{k}$, and $4.2 \mathrm{k}-8.1 \mathrm{k}$ were used (here, we defined an "unstable" emulsion as one that gradually aggregates and causes a phase separation over time, whereas a "stable" emulsion is one that maintains its diameter and does not induce a phase separation as time passes). Using DLS to identify the size distribution of the emulsions, we found that the average diameters of the emulsions formed from the block copolymers coded as $1.5 \mathrm{k}-1.9 \mathrm{k}, 3.2 \mathrm{k}-1.9 \mathrm{k}, 2.9 \mathrm{k}-3.8 \mathrm{k}$, and $4.2 \mathrm{k}-8.1 \mathrm{k}$ were $450,320,870$, and $520 \mathrm{~nm}$, respectively. The results of the static observations suggested that the stability of the w/o emulsions decreased as the $M_{n}$ of PCL decreased, presumably because fewer PCL chains weaken both the formation of emulsion droplets and repulsion between droplets. We used the block copolymers coded as $3.2 \mathrm{k}-1.9 \mathrm{k}$ in the following experiments unless otherwise noted.

Transparent, thin, flexible, free-standing sheets were successfully obtained by spin-coating solutions containing both emulsions and sheet-forming polymers (Figure 2). Figure 3 shows the effects of the number of layers and polymer concentrations used in the sheet preparation stage on the sheet thickness. The thickness increased as the number of layers increased, when the sheets were prepared from PLA or PLA with PLGA (Figure 3A,B). The thickness also increased as the polymer concentrations increased (Figure 3C,D). In both (C) and (D), the number of layers was 11. As shown in Figure 3C, the thickness of the sheets drastically increased as the concentration of PLA increased, because the solution used (the concentration of PLA was over $2 \mathrm{w} / \mathrm{v} \%$ ) was viscous and difficult to spread during the spin-coating process. By contrast, the solution of PLGA-whose average molecular weight was 20,000-was not as viscous; thus, the combination of PLGA and PLA had smaller effects on the sheet thickness than the PLA alone. Furthermore, the addition of PLGA made the sheets more flexible because PLA is crystalline, whereas PLGA is amorphous [54,55]. In two cases, when PLA alone (Figure 3A) and when both PLA and PLGA served as sheet-forming polymers (Figure 3B), we obtained flexible, thin, single-layered sheets with a diameter less than $1 \mu \mathrm{m}$.

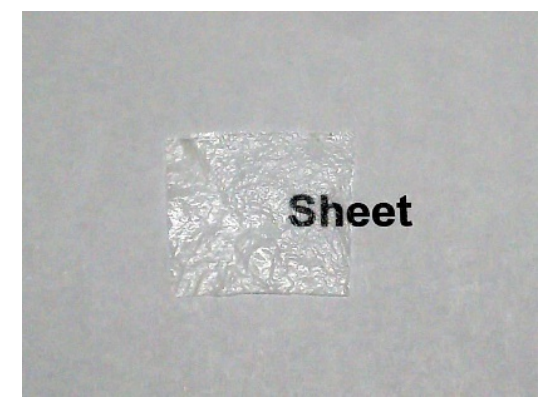

Figure 2. The appearance of a sheet with uniformly dispersed compound-loading sites (the letters " $\mathrm{S}$ " and " $\mathrm{h}$ " in the word "Sheet", written on paper, can be seen through the transparent sheet). 

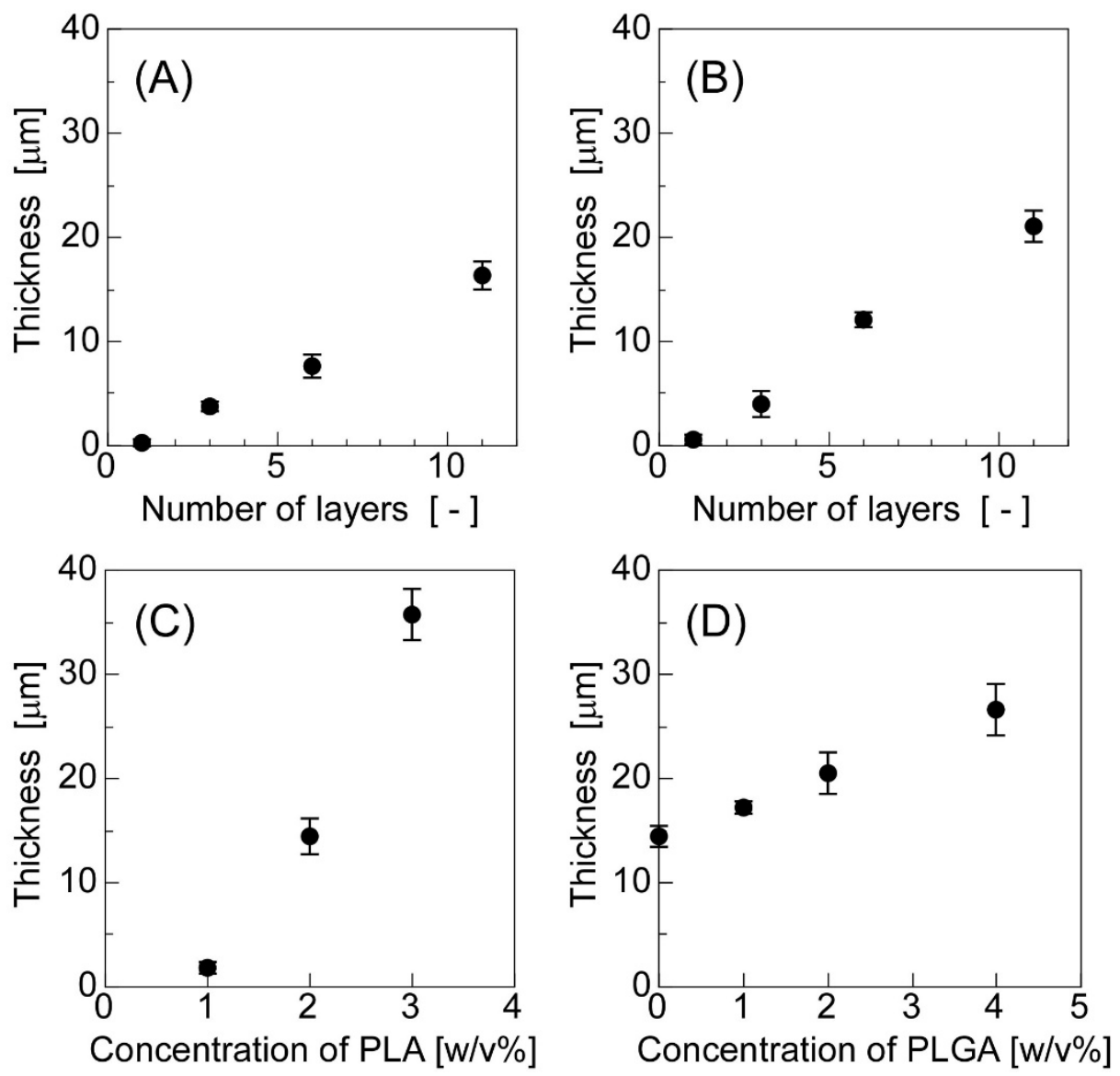

Figure 3. The effects of the number of layers and polymer concentrations on the thickness of the sheets: (A) sheets prepared with a PLA $(2 \mathrm{w} / \mathrm{v} \%)$ solution, (B) sheets prepared with a PLA $(2 \mathrm{w} / \mathrm{v} \%)+$ PLGA $(2 \mathrm{w} / \mathrm{v} \%)$ solution, (C) sheets prepared with a PLA solution (number of layers: 11$)$, and (D) sheets prepared with a PLA $(2 \mathrm{w} / \mathrm{v} \%)+$ PLGA solution (number of layers: 11$)$. The polymer concentrations indicate the values at the preparation stage of the emulsions.

\subsection{The Release of FITC-Dex from the Sheets in Which W/O Emulsions Containing FITC-Dex Were Dispersed}

To determine the factors that affect the release properties of the sheets, we prepared sheets in which w/o emulsions containing a hydrophilic polymer, FITC-dextran, were dispersed, and we evaluated the release of FITC-dextran from the sheets. The release of FITC-dex from the sheets was monitored using a fluorescence spectrometer for 100-150 days.

Figure 4 shows the effect of the number of layers on the sheets' release properties. We found that the number of layers forming the sheets affected the release behavior of FITC-dex from the sheets: an increase in layers could suppress the initial burst release of FITC-dex. Almost the same phenomena were observed when determining the effects of the concentrations of sheet-forming polymers on the release properties of the sheets (Figure 5): An increase in the concentration of sheet-forming polymers could suppress the initial burst release, and decrease the total release of FITC-dex. Presumably, these results can be explained by three phenomena: (1) an increase in the number of layers suppressed the access of the incorporated compounds to the bulk solution because the sheets' thickness increased, (2) an increase in sheet-forming polymers suppressed the diffusion of the incorporated compounds in the sheets, and (3) an increase in sheet-forming polymers suppressed the mobility of the emulsions' surface, making it more difficult to release compounds from the emulsions. These results suggested that the release behavior of compounds from the sheets could be controlled by tuning both the concentration and the composition of sheet-forming polymers. Similar results have been reported concerning drug-incorporated sheets: The concentration and drying method of 
sheet-forming polymers (collagen) affected the release of proteins such as human growth hormone (hGH) [56] and interferon [57], the composition of multi-block poly(ether-ester) matrices affected the release of proteins [58], and thermally induced cross-linking of sheets suppressed the release of hydrophobic drugs [59].

(A)

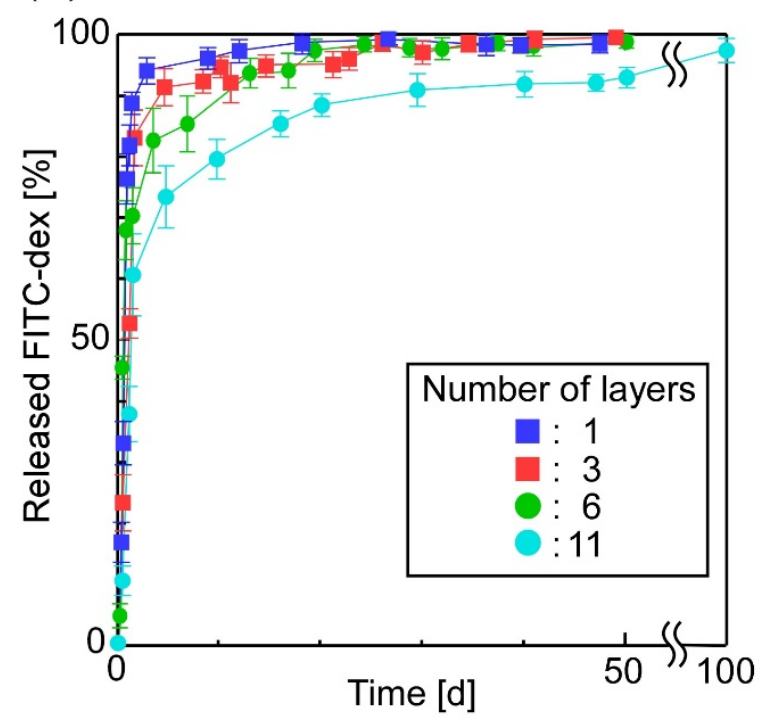

(B)

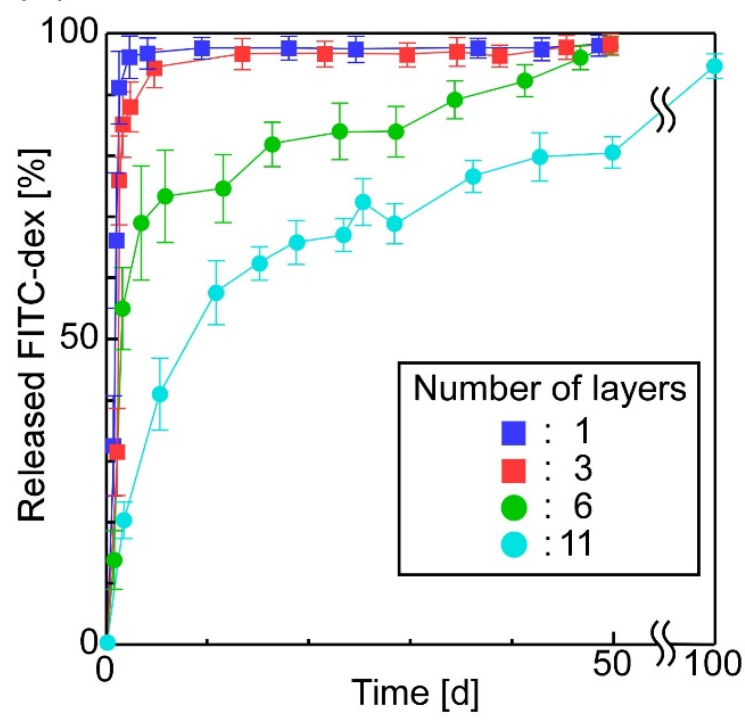

Figure 4. The effect of the number of layers on the release properties of the sheets (the sheet-forming polymers were (A) PLA (2 w/v\%) and (B) PLA (2 w/v\%) + PLGA (2 w/v\%); number of layers: 11).

(A)

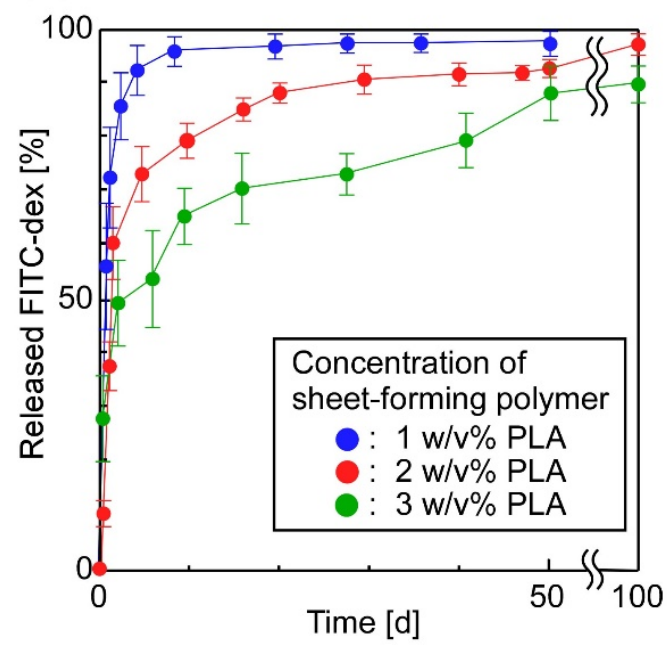

(B)

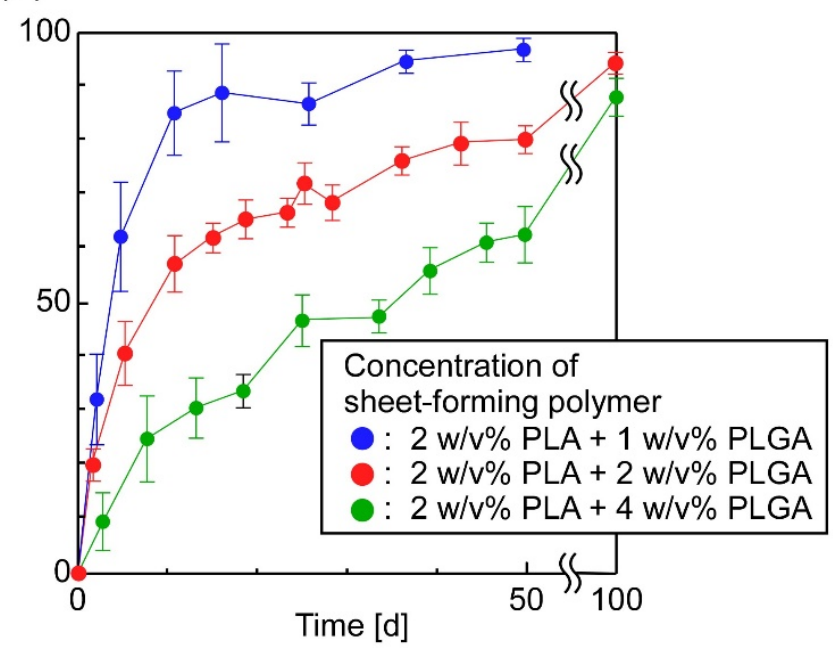

Figure 5. The effect of the concentration of sheet-forming polymers on the release properties of the sheets (the sheet-forming polymers were (A) PLA and (B) PLA (2 w/v\%) + PLGA; number of layers: 11).

Figure 6 shows the effect of the ratios of organic solvent to water in the preparation stage of emulsions on the release properties of the sheets. As shown, the sheets prepared from an emulsion with a ratio of organic solvent to water of 39 , exhibited faster release than sheets prepared from an emulsion with a ratio of 399. In fact, in the former case, almost all the FITC-dex was released from the sheet within a few days because the stability of the w/o emulsions decreased as the volume fraction of water increased. As the volume fraction of water increased, the diameter of water droplets increased, and consequently, the density of emulsions' shells (PCL) decreased. These phenomena induced the fast release of compounds from the emulsions. 


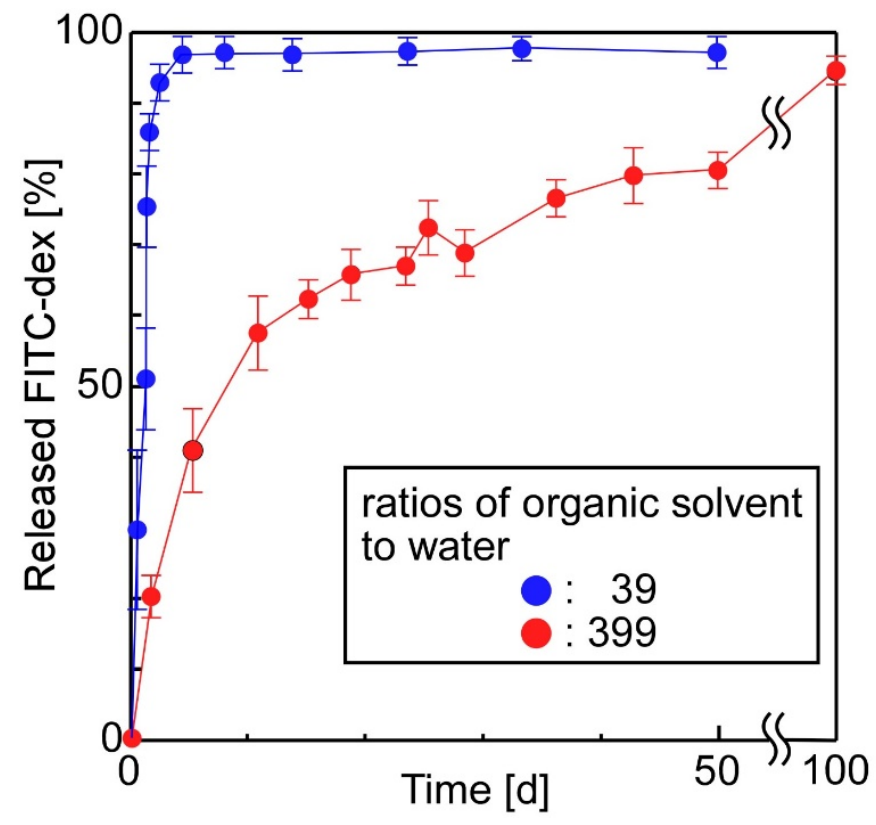

Figure 6. The effect of the ratio of organic solvent to water in the preparation stage of emulsions on the release properties of the sheets (the sheet-forming polymers were PLA $(2 \mathrm{w} / \mathrm{v} \%)+$ PLGA $(2 \mathrm{w} / \mathrm{v} \%)$; number of layers: 11$)$.

Finally, we evaluated the effect of the composition of block copolymers on the release properties of sheets prepared, using PLA and PLGA as sheet-forming polymers. Here, we used block copolymers, where the $M_{n}$ of PEG was lower than the $M_{n}$ of PCL (code $1.5 \mathrm{k}-1.9 \mathrm{k}$, code $2.9 \mathrm{k}-3.8 \mathrm{k}$ and code $4.2 \mathrm{k}-8.1 \mathrm{k}$ ). Figure 7 shows that the release of FITC-dex was suppressed when the block copolymers coded as $1.5 \mathrm{k}-1.9 \mathrm{k}, 2.9 \mathrm{k}-3.8 \mathrm{k}$ and $4.2 \mathrm{k}-8.1 \mathrm{k}$ were used to form emulsions, but was not suppressed when the block copolymer coded as $3.2 \mathrm{k}-1.9 \mathrm{k}$ was used (Figure $5 \mathrm{~A}$ ). This difference in the release behavior was due to the composition of block copolymers; that is, the block copolymers (coded as $1.5 \mathrm{k}-1.9 \mathrm{k}, 2.9 \mathrm{k}-3.8 \mathrm{k}$ and $4.2 \mathrm{k}-8.1 \mathrm{k}$ ) with a higher $M_{\mathrm{n}}$ of PCL than that of PEG presumably formed more stable emulsions than the block copolymers (coded as $3.2 \mathrm{k}-1.9 \mathrm{k}$ ) with a lower $M_{\mathrm{n}}$ of PCL than that of PEG. Furthermore, the compound-release rates of the sheets ranked in descending order, according to the block copolymers' code, as $2.9 \mathrm{k}-3.8 \mathrm{k}, 1.5 \mathrm{k}-1.9 \mathrm{k}$, and $4.2 \mathrm{k}-8.1 \mathrm{k}$. These results support the assumption that PCL, with its higher molecular weight, formed emulsions with outer high-density PCL layers, and consequently, the increased outer PCL layers suppressed the release of FITC-dex from the emulsions. In another report [60], poly(lactide-co-glycolide)-grafted dextran microspheres exhibited slow-release properties when hydrophobic units of grafted polymers increased. These results (including our results) suggest that controlling the amounts of hydrophobic and hydrophilic units at optimal levels helps to regulate the release properties of the materials.

Among the three types of sheet tested in Figure 7, the one whose emulsions were prepared from the block copolymer coded as $4.2 \mathrm{k}-8.1 \mathrm{k}$, released FITC-dex slowly for 50 days and, consequently, released FITC-dex quickly at zero-order for 100 days. Interestingly, we observed an inflection point in the release profiles at around 50 days; that is, the sheet exhibited a "two-step" release behavior. We hypothesize that this interesting phenomenon occurred because the two following steps were necessary in order to release the incorporated compounds from the sheets: (1) in the first period (0-50 days), the compounds had to release from the emulsion across the outer high-density PCL shells and (2) in the next period (50-100 days), the compounds had to diffuse into the polymer networks after the compounds' release from emulsions that were uniformly dispersed in the sheets. A similar slight "two-step" release behavior was observed with the block copolymers coded as $1.5 \mathrm{k}-1.9 \mathrm{k}$ and $2.9 \mathrm{k}-3.8 \mathrm{k}$ at $40 \mathrm{~h}$. These results suggest that the "two-step" release behavior can clearly be observed 
when block copolymers having a higher $M_{n}$ of PCL are used, because the increase in the thickness of the PCL outer shell suppresses the initial release of FITC-dex from the inner space of the emulsions.

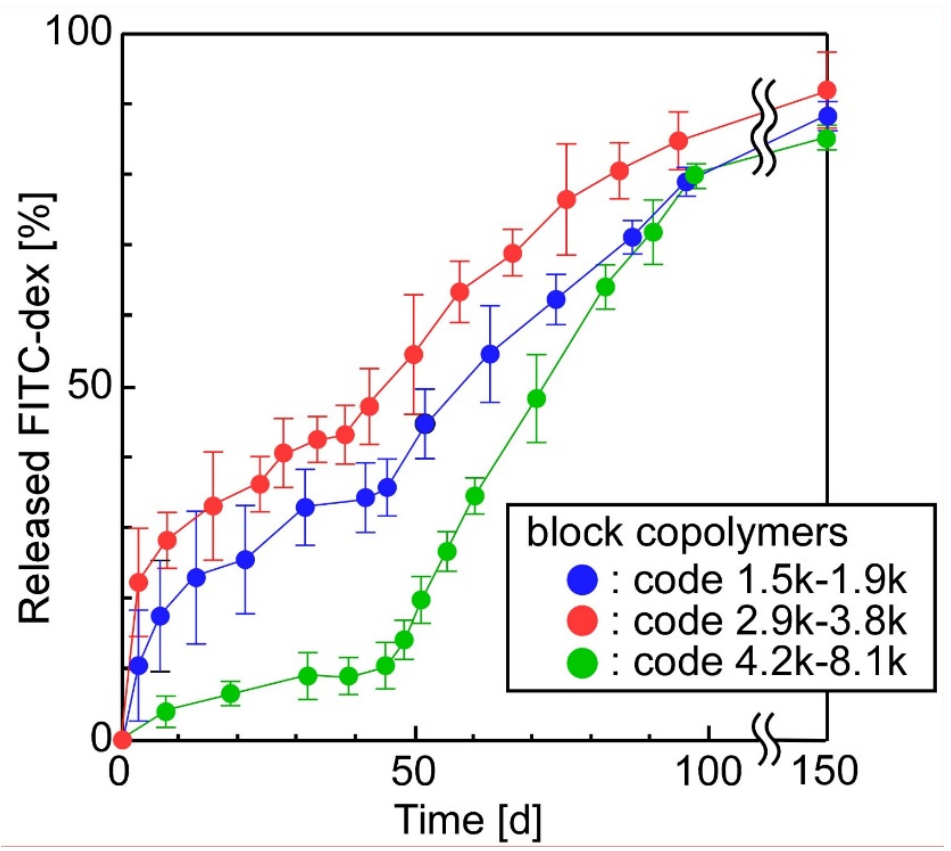

Figure 7. The effect of the composition of block copolymers on the release properties of the sheets (the sheet-forming polymers were PLA ( $2 \mathrm{w} / \mathrm{v} \%)+$ PLGA ( $2 \mathrm{w} / \mathrm{v} \%)$; number of layers: 11$)$.

Combination therapies, in which multiple drugs with different therapeutic effects are used together, have garnered attention as a method for enhancing therapeutic performance in clinical treatments [61,62]. A variety of multiple drug release systems have been proposed, including a silk fibroin protein scaffold in which calcium alginate is embedded [63], electrospun nanofibers [64], a physically formed polymeric micelle-hydrogel composite [65], and a covalently formed polymeric micelle-hydrogel composite [26].

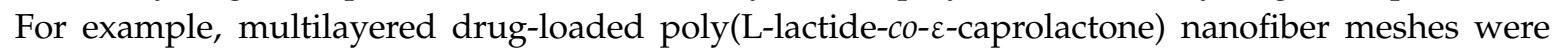
prepared using sequential electrospinning. The mesh consisted of four layers: a drug-loaded mesh, a barrier mesh, another drug-loaded mesh, and a basement mesh [64]. The release profiles of the second drug were regulated by the optimal design of the barrier-mesh. There is significant demand for the continual development of biomaterials designed for the dual release of compounds. Unlike previously reported materials for the dual (or multiple) release of compounds, our sheets (as shown in Figure 7) simultaneously offer three distinct advantages: (1) the preparation requires only physical processes (no chemical reaction is necessary), (2) hydrophilic compounds can be encapsulated despite the hydrophobic nature of the sheets, (3) the time-programmed release of multiple compounds is possible because the release profiles include two steps.

\section{Conclusions}

In the present study, by spin-coating a solution containing w/o emulsion and hydrophobic polymers, we obtained sheets with uniformly dispersed w/o emulsions. We performed release experiments for more than 100 days and clarified the effect that four variables-the number of layers, the type of sheet-forming polymer, the ratio of organic solvent to water, and the composition of block copolymers-had on the release properties of PLA- or PLA/PLGA-emulsion composite sheets. For a variety of sheets, we successfully achieved the sustained-release of compounds from the sheets for 100-150 days. The sustained release of the compounds was successfully achieved because entangled sheet-forming polymer networks suppressed the diffusion of the compounds. Interestingly, we observed an inflection point in the release profiles at 50 days; that is, the sheet 
exhibited a "two-step" release behavior. Although further studies on biocompatibility, cytotoxicity, and cell-material interactions are necessary before biomedical use, the results obtained in the present study strongly suggest that the time-programmed release of multiple compounds from sheets will be a reality in the near future.

Author Contributions: Conceptualization, Y.M.; data curation, H.M., S.S. and Y.M.; methodology, H.M., S.S. and Y.M.; writing of the original draft, H.M.

Funding: This research received no external funding

Conflicts of Interest: The authors declare no conflict of interest.

\section{References}

1. Saha, K.; Tsuji, H. Effects of rapid crystallization on hydrolytic degradation and mechanical properties of poly(L-lactide-co-e-caprolactone). React. Funct. Polym. 2006, 66, 1362-1372. [CrossRef]

2. Gao, Y.; Kong, L.; Zhang, L.; Gong, Y.; Chen, G.; Zhao, N.; Zhang, X. Improvement of mechanical properties of poly(DL-lactide) films by blending of poly(3-hydroxybutyrate-co-3-hydroxyhexanoate). Eur. Polym. J. 2006, 42, 764-775. [CrossRef]

3. Xu, C.; Yuan, D.; Fu, L.; Chen, Y. Physical blend of PLA/NR with co-continuous phase structure: Preparation, rheology property, mechanical properties and morphology. Polym. Test. 2014, 37, 94-101. [CrossRef]

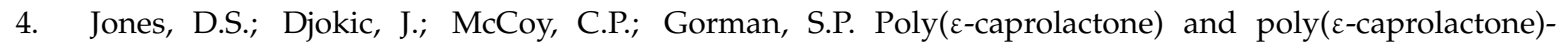
polyvinylpyrrolidoneiodine blends as ureteral biomaterials: Characterisation of mechanical and surface properties, degradation and resistance to encrustation in vitro. Biomaterials 2002, 23, 4449-4458. [CrossRef]

5. Liu, Y.; Shao, J.; Sun, J.; Bian, X.; Feng, L.; Xiang, S.; Sun, B.; Chen, Z.; Li, G.; Chen, X. Improved mechanical and thermal properties of PLLA by solvent blending with PDLA-b-PEG-b-PDLA. Polym. Degrad. Stab. 2014, 101, 10-17. [CrossRef]

6. Orava, E.; Korventausta, J.; Rosenberg, M.; Jokinen, M.; Rosling, A. In vitro degradation of porous poly(DL-lactide-co-glycolide) (PLGA)/bioactive glass composite foams with a polar structure. Polym. Degrad. Stab. 2007, 92, 14-23. [CrossRef]

7. Park, S.B.; Sakamoto, J.; Sung, M.H.; Uyama, H. pH-controlled degradation and thermal stability of a porous poly $(\gamma$-glutamic acid) monolith crosslinked with an oxazoline-functionalized polymer. Polym. Degrad. Stab. 2014, 99, 99-104. [CrossRef]

8. Moura, L.I.; Dias, A.M.; Carvalho, E.; de Sousa, H.C. Recent advances on the development of wound dressings for diabetic foot ulcer treatment: A review. Acta Biomater. 2013, 9, 7093-7114. [CrossRef] [PubMed]

9. Fajardo, A.R.; Lopes, L.C.; Caleare, A.O.; Britta, E.A.; Nakamura, C.V.; Rubira, A.F.; Muniz, E.C. Silver sulfadiazine loaded chitosan/chondroitin sulfate films for a potential wound dressing application. Mater. Sci. Eng. C 2013, 33, 588-595. [CrossRef]

10. Liakos, I.; Rizzello, L.; Scurr, D.J.; Pompa, P.P.; Bayer, I.S.; Athanassiou, A. All-natural composite wound dressing films of essential oils encapsulated in sodium alginate with antimicrobial properties. Int. J. Pharm. 2014, 463, 137-145. [CrossRef]

11. Felgueiras, H.P.; Amorim, M.T.P. Functionalization of electrospun polymeric wound dressings with antimicrobial peptides. Colloids Surf. B Biointerfaces 2017, 156, 133-148. [CrossRef] [PubMed]

12. Simões, D.; Miguel, S.P.; Ribeiro, M.P.; Coutinho, P.; Mendonça, A.G.; Correia, I.J. Recent advances on antimicrobial wound dressing: A review. Eur. J. Pharm. Biopharm. 2018, 127, 130-141. [CrossRef]

13. Lao, L.L.; Venkatraman, S.S. Paclitaxel release from single and double-layered poly(DL-lactide-coglycolide)/poly(L-lactide) film for biodegradable coronary stent application. J. Biomed. Mater. Res. A 2008, 87A, 1-7. [CrossRef] [PubMed]

14. Lin, M.; Meng, S.; Zhong, W.; Cai, R.; Du, Q.; Tomasik, P. Novel drug-loaded gelatin films and their sustained-release performance. J. Biomed. Mater. Res. B Appl. Biomater. 2009, 90B, 939-944. [CrossRef]

15. Lei, L.; Liu, X.; Guo, S.; Tang, M.; Cheng, L.; Tian, L. 5-Fluorouracil-loaded multilayered films for drug controlled releasing stent application: Drug release, microstructure, and ex vivo permeation behaviors. J. Controll. Release 2010, 146, 45-53. [CrossRef] 
16. Steele, T.W.J.; Huang, C.L.; Widjaja, E.; Boey, F.Y.C.; Loo, J.S.C.; Venkatraman, S.S. The effect of polyethylene glycol structure on paclitaxel drug release and mechanical properties of PLGA thin films. Acta Biomater. 2011, 7, 1973-1983. [CrossRef] [PubMed]

17. Ro, A.J.; Falotico, R.; Dave, V. Microstructure and drug-release studies of sirolimus-containing poly(lactide-co-glycolide) films. J. Biomed. Mater. Res. B Appl. Biomater. 2011, 97B, 30-39. [CrossRef]

18. Tang, M.; Hou, J.; Lei, L.; Liu, X.; Guo, S.; Wang, Z.; Chen, K. Preparation, characterization and properties of partially hydrolyzed ethylene vinyl acetate copolymer films for controlled drug release. Int. J. Pharm. 2010, 400, 66-72. [CrossRef]

19. Park, Y.J.; Ku, Y.; Chung, C.P.; Lee, S.J. Controlled release of platelet-derived growth factor from porous poly(L-lactide) membranes for guided tissue regeneration. J. Controll. Release 1998, 51, 201-211. [CrossRef]

20. Shah, N.J.; Macdonald, M.L.; Beben, Y.M.; Padera, R.F.; Samuel, R.E.; Hammond, P.T. Tunable dual growth factor delivery from polyelectrolyte multilayer films. Biomaterials 2011, 32, 6183-6193. [CrossRef]

21. Murakami, Y.; Yokoyama, M.; Okano, T.; Nishida, H.; Tomizawa, Y.; Endo, M.; Kurosawa, H. A novel synthetic tissue-adhesive hydrogel using a crosslinkable polymeric micelle. J. Biomed. Mater. Res. 2007, 80A, 421-427. [CrossRef] [PubMed]

22. Murakami, Y.; Yokoyama, M.; Nishida, H.; Tomizawa, Y.; Kurosawa, H. A simple hemostasis model for the quantitative evaluation of hydrogel-based local hemostatic biomaterials on tissue surface. Colloids Surf. B Biointerfaces 2008, 65, 186-189. [CrossRef] [PubMed]

23. Murakami, Y.; Yokoyama, M.; Nishida, H.; Tomizawa, Y.; Kurosawa, H. In vivo and in vitro evaluation of gelation and hemostatic properties of a novel tissue-adhesive hydrogel containing a cross-linkable polymeric micelle. J. Biomed. Mater. Res. B Appl. Biomater. 2009, 91, 102-108. [CrossRef] [PubMed]

24. Uchida, Y.; Fukuda, K.; Murakami, Y. The hydrogel containing a novel vesicle-like soft crosslinker, a "trilayered" polymeric micelle, shows characteristic rheological properties. J. Polym. Sci. B Polym. Phys. 2013, 51, 124-131. [CrossRef]

25. Ito, T.; Yoshida, C.; Murakami, Y. Design of novel sheet-shaped chitosan hydrogel for wound healing: A hybrid biomaterial consisting of both PEG-grafted chitosan and crosslinkable polymeric micelles acting as drug containers. Mater. Sci. Eng. C 2013, 33, 3697-3703. [CrossRef]

26. Murata, M.; Uchida, Y.; Takami, T.; Ito, T.; Anzai, R.; Sonotaki, S.; Murakami, Y. Dual drug release from hydrogels covalently containing polymeric micelles that possess different drug release properties. Colloids Surf. B Biointerfaces 2017, 153, 19-26. [CrossRef]

27. Yoshida, C.; Uchida, Y.; Ito, T.; Takami, T.; Murakami, Y. Chitosan gel sheet containing polymeric micelles: Synthesis and gelation properties of PEG-grafted chitosan. Materials 2017, 10, 1075. [CrossRef]

28. Ito, T.; Takami, T.; Uchida, Y.; Murakami, Y. Chitosan gel sheet containing drug carriers with controllable drug-release properties. Colloids Surf. B: Biointerfaces 2018, 163, 257-265. [CrossRef]

29. Moroishi, H.; Yoshida, C.; Murakami, Y. A free-standing, sheet-shaped, "hydrophobic" biomaterial containing polymeric micelles formed from poly(ethylene glycol)-poly(lactic acid) block copolymer for possible incorporation/release of "hydrophilic" compounds. Colloids Surf. B Biointerfaces 2013, 102, 597-603. [CrossRef]

30. Anzai, R.; Murakami, Y. Poly( $\varepsilon$-caprolactone) (PCL)-polymeric micelle hybrid sheets for the incorporation and release of hydrophilic compounds. Colloids Surf. B Biointerfaces 2015, 127, 292-299. [CrossRef]

31. Anzai, R.; Takami, T.; Uchida, Y.; Murakami, Y. Poly( $\varepsilon$-caprolactone) (PCL) hybrid sheets containing polymeric micelles: Effects of inner structures on the material properties of the sheet. Mater. Sci. Eng. C 2017, 72, 325-331. [CrossRef] [PubMed]

32. Kanakubo, Y.; Ito, F.; Murakami, Y. Novel one-pot facile technique for preparing nanoparticles modified with hydrophilic polymers on the surface via block polymer-assisted emulsification/evaporation process. Colloids Surf. B Biointerfaces 2010, 78, 85-91. [CrossRef]

33. Takami, T.; Murakami, Y. Development of PEG-PLA/PLGA microparticles for pulmonary drug delivery prepared by a novel emulsification technique assisted with amphiphilic block copolymers. Colloids Surf. B Biointerfaces 2011, 87, 433-438. [CrossRef] [PubMed]

34. Takami, T.; Murakami, Y. Unexpected and successful "one-step" formation of porous polymeric particles only by mixing organic solvent and water under "low-energy-input" conditions. Langmuir 2014, 30, 3329-3336. [CrossRef] 
35. Yoneki, N.; Takami, T.; Ito, T.; Anzai, R.; Fukuda, K.; Kinoshita, K.; Sonotaki, S.; Murakami, Y. One-pot facile preparation of PEG-modified PLGA nanoparticles: Effects of PEG and PLGA on release properties of the particles. Colloids Surf. A Physicochem. Eng. Asp. 2015, 469, 66-72. [CrossRef]

36. Nishimura, S.; Takami, T.; Murakami, Y. Porous PLGA microparticles formed by "one-step" emulsification forpulmonary drug delivery: The surface morphology and theaerodynamic properties. Colloids Surf. B Biointerfaces 2017, 159, 318-326. [CrossRef] [PubMed]

37. Uchida, Y.; Murakami, Y. Trilayered polymeric micelle: A newly developed macromolecular assembly that can incorporate hydrophilic compounds. Colloids Surf. B Biointerfaces 2010, 79, 198-204. [CrossRef]

38. Uchida, Y.; Murakami, Y. Successful preferential formation of a novel macromolecular assembly-trilayered polymeric micelle-that can incorporate hydrophilic compounds: The optimization of factors affecting the micelle formation from amphiphilic block copolymers. Colloids Surf. B Biointerfaces 2011, 84, 346-353. [CrossRef]

39. Pang, X.; Du, H.-L.; Zhang, H.-Q.; Zhai, Y.-J.; Zhai, G.-X. Polymer-drug conjugates: Present state of play and future perspectives. Drug Discov. Today 2013, 18, 1316-1322. [CrossRef]

40. Kolate, A.; Baradia, D.; Patil, S.; Vhora, I.; Kore, G.; Misra, A. PEG: A versatile conjugating ligand for drugs and drug delivery systems. J. Controll. Release 2014, 192, 67-81. [CrossRef]

41. Murakami, Y.; Hirata, A. Complex between $\alpha$-chymotrypsin and poly(ethylene glycol) catalytically active in organic media. Biotechnol. Tech. 1999, 13, 545-548. [CrossRef]

42. Murakami, Y.; Hoshi, R.; Hirata, A. Borate buffer dramatically enhances the activity of poly(ethylene glycol)- $\alpha$-chymotrypsin complex catalytically active in anhydrous isooctane than conventional phosphate buffer even at low concentration. Biotechnol. Lett. 2001, 23, 125-129. [CrossRef]

43. Murakami, Y.; Hirata, A. Enzymatic synthesis of peptides: Review. Seibutsu-Kogaku Kais. 1998, 76, $238-254$.

44. Wanga, B.; Zheng, H.; Chang, M.-W.; Ahmad, Z.; Li, J.-S. Hollow polycaprolactone composite fibers for controlled magnetic responsive antifungal drug release. Colloids Surf. B Biointerfaces 2016, 145, 757-767. [CrossRef] [PubMed]

45. Yang, G.; Lin, H.; Rothrauff, B.B.; Yu, S.; Tuan, R.S. Multilayered polycaprolactone/gelatin fiber-hydrogel composite for tendon tissue engineering. Acta Biomater. 2016, 35, 68-75. [CrossRef] [PubMed]

46. Song, J.; Gao, H.; Zhu, G.; Cao, X.; Shi, X.; Wang, Y. The preparation and characterization of polycaprolactone/graphene oxide biocomposite nanofiber scaffolds and their application for directing cell behaviors. Carbon 2015, 95, 1039-1050. [CrossRef]

47. Zhang, Q.; Lv, S.; Lu, J.; Jiang, S.; Lin, L. Characterization of polycaprolactone/collagen fibrous scaffolds by electrospinning and their bioactivity. Int. J. Biol. Macromol. 2015, 76, 94-101. [CrossRef]

48. Ramot, Y.; Haim-Zada, M.; Domb, A.J.; Nyska, A. Biocompatibility and safety of PLA and its copolymers. Adv. Drug. Deliv. Rev. 2016, 107, 153-162. [CrossRef] [PubMed]

49. Lee, B.K.; Yun, Y.; Park, K. PLA micro- and nano-particles. Adv. Drug. Deliv. Rev. 2016, 107, $176-191$. [CrossRef]

50. Tyler, B.; Gullotti, D.; Mangraviti, A.; Utsuki, T.; Brem, H. Polylactic acid (PLA) controlled delivery carriers for biomedical applications. Adv. Drug. Deliv. Rev. 2016, 107, 163-175. [CrossRef] [PubMed]

51. Chereddy, K.K.; Payen, V.L.; Préat, V. PLGA: From a classic drug carrier to a novel therapeutic activity contributor. J. Controll. Release 2018, 289, 10-13. [CrossRef] [PubMed]

52. Mir, M.; Ahmed, N.; Rehman, A.U. Recent applications of PLGA based nanostructures in drug delivery. Colloids Surf. B Biointerfaces 2017, 159, 217-231. [CrossRef] [PubMed]

53. Zhao, W.; Li, J.; Jin, K.; Liu, W.; Qiu, X.; Li, C. Fabrication of functional PLGA-based electrospun scaffolds and their applications in biomedical engineering. Mater. Sci. Eng. C 2016, 59, 1181-1194. [CrossRef] [PubMed]

54. Santos, F.A.; Lulianelli, G.C.V.; Tavares, M.I.B. Development and properties evaluation of bio-based PLA/PLGA blend films reinforced with microcrystalline cellulose and organophilic silica. Polym. Eng. Sci. 2017, 57, 464-472. [CrossRef]

55. Makadia, H.K.; Siegel, S.J. Poly lactic-co-glycolic acid (PLGA) as biodegradable controlled drug delivery carrier. Polymers 2011, 3, 1377-1397. [CrossRef] [PubMed]

56. Maeda, M.; Kadota, K.; Kajihara, M.; Sano, A.; Fujioka, K. Sustained release of human growth hormone (hGH) from collagen film and evaluation of effect on wound healing in $\mathrm{db} / \mathrm{db}$ mice. J. Controll. Release 2001, 77, 261-272. [CrossRef] 
57. Fujioka, K.; Takada, Y.; Sato, S.; Miyata, T. Novel delivery system for proteins using collagen as a carrier material: The minipellet. J. Controll. Release 1995, 33, 307-315. [CrossRef]

58. van Dijkhuizen-Radersma, R.; Métairie, S.; Roosma, J.R.; de Groot, K.; Bezemer, J.M. Controlled release of proteins from degradable poly(ether-ester) multiblock copolymers. J. Controll. Release 2005, 101, 175-186. [CrossRef] [PubMed]

59. Kim, B.-S.; Park, S.W.; Hammond, P.T. Hydrogen-bonding layer-by-layer-assembled biodegradable polymeric micelles as drug delivery vehicles from surfaces. ACS Nano 2008, 2, 386-392. [CrossRef]

60. Kakizawa, Y.; Nishio, R.; Hirano, T.; Koshi, Y.; Nukiwa, M.; Koiwa, M.; Michizoe, J.; Ida, N. Controlled release of protein drugs from newly developed amphiphilic polymer-based microparticles composed of nanoparticles. J. Controll. Release 2010, 142, 8-13. [CrossRef]

61. Kakeji, Y.; Oki, E.; Egashira, A.; Sadanaga, N.; Takahashi, I.; Morita, M.; Emi, Y.; Maehara, Y. Phase II study of biweekly docetaxel and S-1 combination therapy for advanced or recurrent gastric cancer. Oncology 2009, 77, 49-52. [CrossRef]

62. Bathe, O.F.; Ernst, S.; Sutherland, F.R.; Dixon, E.; Butts, C.; Bigam, D.; Porter, G.A.; Koppel, J.; Dowden, S. A phase II experience with neoadjuvant irinotecan (CPT-11), 5-fluorouracil (5-FU) and leucovorin (LV) for colorectal liver metastases. BMC Cancer 2009, 9, 156. [CrossRef]

63. Mandal, B.B.; Kundu, S.C. Calcium alginate beads embedded in silk fibroin as 3D dual drug releasing scaffolds. Biomaterials 2009, 28, 5170-5177. [CrossRef] [PubMed]

64. Okuda, T.; Tominaga, K.; Kidoaki, S. Time-programmed dual release formulation by multilayered drug-loaded nanofiber meshes. J. Controll. Release 2010, 143, 258-264. [CrossRef] [PubMed]

65. Wei, L.; Cai, C.; Lin, J.; Chen, T. Dual-drug delivery system based on hydrogel/micelle composites. Biomaterials 2009, 30, 2606-2613. [CrossRef] [PubMed]

(C) 2018 by the authors. Licensee MDPI, Basel, Switzerland. This article is an open access article distributed under the terms and conditions of the Creative Commons Attribution (CC BY) license (http:/ / creativecommons.org/licenses/by/4.0/). 